\title{
Obstacles and Disaster Risk Reduction: A Survey of Memphis Organizations
}

\author{
Abdul-Akeem Sadiq ${ }^{1}$ and Christopher M. Weible ${ }^{2}$
}

Sadiq, A. A., \& Weible, C. M. (2010). Obstacles and disaster risk reduction: Survey of Memphis organizations. Natural Hazards Review, 11(3), 110-117. DOI:

(ASCE)NH.1527-6996.0000016

\footnotetext{
${ }^{1}$ Visiting Assistant Professor, University of North Texas, College of Public Affairs and Community Service, P.O. Box 310617, Denton, TX 76203 (corresponding author). E-mail: akeemsiq@ hotmail.com or asadiq@unt.edu

${ }^{2}$ Asst. Professor, University of Colorado Denver, School of Public Affairs, Denver, CO 80217-3364. Email: chris.weible@ucdenver.edu
} 


\begin{abstract}
The disaster management literature is replete with surveys at the community and household levels. However, few exist at the organizational level. This study attempts to fill this void by examining the effect of organizational obstacles on disaster risk reduction. The data come from a survey of 227 organizations in Memphis, Tennessee. This study investigates three obstacles to disaster risk reduction: lack of organizational support, lack of information, and lack of financial resources. The findings show that organizations are more likely to engage in low-effort activities indirectly related to risk reduction and are less likely to engage in high-effort activities directly related to risk reduction. The most important obstacle is lack of information about the frequency of disasters, magnitude of disasters, or organizational benefits of reducing disaster risks. Lack of financial resources and lack of organizational support are sometimes positively associated with risk-reducing activities, suggesting that, when organizations engage in risk-reducing activities, some obstacles become more apparent. The study concludes with implications, limitations, and future research strategies.
\end{abstract}

CE Database subject headings: Disasters; risk management; information management; organizations; Tennessee. 


\section{Introduction}

Of all the goals that organizations aspire, the most important is probably survival. Disasters threaten the survival of organizations by disrupting services and destroying properties, lifelines, and life. To mitigate the threats from disasters, organizations may engage in a number of risk-reducing activities, such as bracing shelves and equipment, purchasing earthquake or flood insurance, developing an emergency plan, buying generators, and storing supplies (Dahlhamer and D’Souza 1997). Not all organizations engage in risk-reducing activities. Indeed, organizations face a number of obstacles that impede any effort to reduce disaster risk.

This study investigates three common obstacles (lack of organizational support, lack of information, and lack of financial resources) that prevent organizations from undertaking risk-reducing activities. In doing so, this study addresses two research questions: (i) What risk-reducing activities do organizations engage in? (ii) To what extent do obstacles affect the adoption of risk-reducing activities? The former question is important in providing a survey of the status quo. The latter question is crucial in providing a basis for developing strategies for improving hazard mitigation and disaster preparedness policies and programs.

The data come from a survey administered to a sample of 227 organizations in Memphis/Shelby County, Tennessee in the fall of 2006. Memphis makes for an interesting case study, in part, because it is located in the New Madrid Seismic Zone (NMSZ), an area of earthquake hazard (United States Geological Survey (USGS) 1998).

This study starts by summarizing the literature on obstacles in disaster management and specifying expectations. The case study and methods of data collection 
follow. The bulk of the study lie in the results section, which shows that organizations are more likely to engage in low-effort activities that are often precursors to reducing risks than high-effort activities more directly related to reducing risks. The findings also show that lack of information tends to be a bigger obstacle than lack of organizational support or financial resources. The conclusions discuss policy implications, limitations, and recommendations for future research.

\section{Background}

Despite the pivotal role that organizations play in the economic, political, and social wellbeing of a society, the disaster management literature has largely neglected organizational level research (Tierney 1997; Webb et al. 2000). Among the large-n quantitative studies-in particular-the focus has largely been either on household surveys (Jackson 1981; Davis 1989; Dooley et al. 1992; Edwards 1993; Farley 1998; Atwood and Major 2000) or on surveys of policy elites active in a community (Drabek et al. 1983; Mushkatel and Nigg 1987; Berke and Beatley 1992; May and Birkland 1994; Burby et al. 2000; Wood 2004). The reasons for this neglect are three fold: (i) Organizations are difficult to sample and survey in large numbers; (ii) The theoretical lines of inquiry usually direct research activities toward disaster awareness and response among regular citizen or among decision makers; and (iii) Some organizations are wary of the potential consequences of divulging disaster-related information (Auf der Heide 1989). In relation to this current analysis, the few studies focusing on the organizational level suggest that organizations in Memphis/Shelby County do little to prepare for disasters (e.g., Nigg and Tierney 1994; Dahlhamer and D'Souza 1997; Webb et al. 2000). Despite the neglect of organizational-level research, a number of factors from the disaster management 
literature as well as organizational theory help explain why an organization engages in risk-reducing activities. This study investigates the affect of three categories of these factors: information, financial resources, and organizational support.

One of the most important factors affecting organizational activities is information. For example, information is often at the center of resource exchange that drive organizational decisions (Pfeffer and Salancik 1978) or as a vital stimulus for organizational formation and survival (Aldrich and Pfeffer 1976; DiMaggio and Powell 1983). Given the challenges of prediction, an important ingredient for disaster mitigation and preparations is acquiring and using information (Major 1998). Such information can alert a population to an impending disaster or various disaster risks. Other information comes in the form of strategies or alternatives to help individuals, organizations, and communities prepare for, or mitigate, disasters. Sources of disaster information include, but are not limited to, personal communication with other people, news media, government agencies, private organizations, non-profits, and research institutions.

The disaster management literature has focused much on the role of information in household preparedness for earthquakes. For example, information on earthquake risks can induce households to take preparatory action (Jackson and Mukerjee 1974; Sullivan et al. 1977; Palm 1981; Turner 1983; Russell et al. 1995; Flynn et al. 1999; Atwood and Major 2000; Celsi et al. 2005). A notable example is the impact of Iben Browning's forecast that a major earthquake in the NMSZ would occur around December 3, 1990 (e.g., Farley et al. 1993; Showalter 1993; Atwood and Major 2000). Although, some households believed Browning's forecast, most were ambivalent, many planned schedule 
changes, and fewer than those that planned to make changes actually did (Farley et al. 1993). Similarly, Showalter (1993) found that respondents indicated that the prediction made them more aware and prepared for future earthquakes.

This study investigates three information-related organizational obstacles: (i) lack of information about the frequency and magnitude of disasters (ii) lack of information about the potential impact of disasters, and (iii) unclear organizational benefits from disaster planning and mitigation. The magnitude and frequency relate to the force and relative timing of the actual event. The impact of disasters deals with the outcome or effect from the event on an organization or the organization's community. Unclear organizational benefits mean that an organization is oblivious of the gains from disaster planning. Overall, the expectation is that organizations will be less likely to engage in risk-reducing activities if they lack information about the frequency and magnitude, impacts, or organizational benefits from reducing risks.

Any organizational activity, especially preparing and mitigating disasters requires time, money, and effort (Pfeffer and Salancik 1978; Wyner and Mann 1986; May and Birkland 1994). In their study of local regulatory efforts to reduce earthquake risk, May and Birkland (1994) found that community resources are important in the local government effort and willingness to adopt seismic risk-reducing measures. Lack of financial resources can constrain the adoption of earthquake mitigation policies (Bostrom et al. 2006). This analysis focuses on whether organizations consider lack of financial resources as an obstacle to disaster risk reduction. The expectation is that organizations will be less likely to engage in risk-reducing activities if they lack financial resources. 
Support from different levels within an organization provides a variety of functions that affect the probability of success (Selznick 1957; Yukl 1989; Bass 1997). From a broader perspective, researchers have documented the pivotal role policy entrepreneurs or champions play in the policymaking process (e.g., Kingdon 1984; Prater and Lindell 2000; Wood 2004; Olshansky 2005). These entrepreneurs are willing to, among other strategies, mobilize support for the issue if necessary (Berke and Beatley 1992). Leadership support is just as important in organizations as it is in the policymaking arena. Kaufman (1971) discusses the importance of internal organizational forces that can provide support or opposition to organizational change. In the context of disasters, the support from upper-level management is crucial in the adoption of disaster risk-reducing measures but support at the lower-levels is also important in terms of execution. The expectation is that organizations will be less likely to engage in riskreducing activities if support from the upper- or lower- levels within the organization is a major obstacle.

Given these three common obstacles (lack of information, financial resources, or support) this paper proceeds to explain the degree that organizations engage in different types of risk-reducing activities. At the household level, risk-reducing activities might include purchasing earthquake insurance, shutting off utilities, developing emergency plans, buying first aid kits, and storing food and water (Davis 1989; Mileti and O’Brien 1992; Edward 1993; Farley et al. 1993). At the community level or policy subsystem level, risk-reducing activities include building codes, zoning ordinances, and land use planning (Olshansky 1994; Flynn et al. 1999). A common trend in the literature is to offer subjects an extensive list of risk-reducing activities to capture the range of their 
behaviors (e.g., Davis 1989; Edwards 1993; Lindell and Prater 2002). For this paper with its organizational focus, a range of risk-reducing activities are studied (e.g., discuss shortterm responses to disasters, engage in structural mitigation, or engage in nonstructural mitigation) as well as prerequisite activities (e.g., mention potential disasters in an organizational meeting).

Two controls are important for both practical and theoretical reasons but are not the focus of this particular analysis. The first control is organizational size with the expectation that larger organizations will have more resources to invest in risk-reducing activities than smaller organizations. Such a resource argument is common in the literature on disaster risk reduction at the household (Mileti 1999), community (May and Birkland 1994; Wood 2004), and organizational level (Tierney 2006). The second control is the sector in which an organization belongs, with a particular emphasis on education, health, and wholesale and retail. Evidence in the disaster literature indicates that some sectors e.g., finance, insurance, and real estate, do more to prepare for disasters than do others (Dahlhamer and D’Souza 1997).

\section{Case Study}

We examined a sample of organizations in Memphis/Shelby County, Tennessee. One of the most-studied risks facing the Memphis community is from earthquakes located in the NMSZ. Earthquakes are the biggest disaster risk in the Memphis area (Charlier 2005). The three most powerful earthquakes in the United States (magnitude 7.0-8.1) occurred in the New Madrid region (Memphis/Shelby County were not a settlement then) between December 16, 1811 and February 7, 1812 (USGS 1993; USGS 
1998). While many dispute the characterization of the risk, the USGS (1998) estimated that there is higher than $90 \%$ probability of a moderate earthquake (magnitude 6-7) hitting the New Madrid region within the next 50 years. In general, the seismic risk from the NMSZ is of low probability but high consequences (Olshansky 1994). Still, Memphis faces threats from other disasters, such as floods, tornadoes, ice storms, chemical spills, fires, severe storms, violent crimes, and toxic releases. A July 22, 2003 windstorm (later called Hurricane Elvis) left over 300,000 utility consumers in the dark; it took two weeks to restore power for everyone (Shepard 2003).

A study of organizations in Memphis/Shelby County makes for an interesting case for several reasons. The rarity of major earthquakes in Memphis/Shelby County in recent time, poses challenges for organizations in deciding to reduce risk. Absence of such disasters could make organizations apathetic and reluctant to adopt measures to reduce disaster risks (May 1986; Lindell and Perry 2007). In addition, disaster researchers have conducted myriad earthquake and disaster studies on the west coast, especially in California (Jackson and Mukerjee 1974; Kiecolt and Nigg 1982; Mulilis and Duval 1995; Argothy 2003; May and Wood 2003; Wood 2004; Celsi et al. 2005). However, very few studies have analyzed responses to disaster risks in Memphis (Edwards 1993; Nigg and Tierney 1994; Dahlhamer and D’Souza 1997; Webb et al. 2000) and few in regions where risks have low probabilities and high consequences (Mushkatel and Nigg 1987; Olshansky 1994; Farley 1998; Major 1998; Atwood and Major 2000). 


\section{Methodology}

The data gathering procedure occurred in two phases. In the first phase, the research team conducted 15 exploratory interviews with 15 professional managers in Memphis/Shelby County in the spring and summer of 2006. The interviews consisted of open-ended questions, conducted in person or via telephone. Interview questions addressed attitudes toward hazard risk management and risk information, as well as organizational actions with respect to risk. The interviews took approximately 30-60 minutes each. The research team typed up the interviews and returned them to the interviewees for comments and approval.

The second phase consisted of a survey administered in fall of 2006. The interviews informed the survey questions. The research team mailed surveys to a stratified and partially random sample of 733 organizations in Memphis/Shelby County. With the help of the Memphis Regional Chambers of Commerce, the research team queried an online reference service, ReferenceUSA using the "number of employees" as a key index variable. The categories ranged from no employee to over 9999 employees. The research team re-categorized "number of employees" into seven categories (1-9, 10$19,20-49,50-99,100-249,250-499$, and $\geq 500$ ) and stratified the population by employee size to allow the survey and representation of all organizational sizes in the Memphis Metropolitan Area.

The research team then extracted 100 organizations from the first six categories and 101 from the last category, added all 32 utility companies, and surveyed these 733 organizations. The research team delivered the surveys following a modification of the Dillman's total design method (Dillman 2000). The research team mailed a letter on 
university letterhead to each of the 733 organizations, describing the study and seeking their participation. The research team then mailed the first batch of surveys and followed-up with postcards, and then the second batch of surveys. The research team addressed the surveys to owners and risk managers of these organizations. The most frequent respondents were the manager $(n=51)$, owner $(n=44)$, President $(n=37)$, Chief and Executive Officer $(n=34)$. A variety of organizational representatives completed the rest including Vice Presidents, Executive Directors, Principals, and a Religious Leader. The response rate is about $31 \%, 227$ organizations returned the survey but ten declined to participate in the study for various reasons (e.g. "business is not being fully operational" and "due to the private nature of our business").

\section{Variable Measurement}

\section{Dependent variables}

The dependent variables are ten different risk-reducing activities that organizations can undertake. The survey asked with $1=$ yes and $0=$ no for the following question: "Has your organization engaged in any of these activities over the past year?" The list of activities included:

1. Mentioned a potential disaster in an organizational meeting;

2. Discussed in an organizational meeting short-term responses to disasters;

3. Engage in non-structural mitigation measures (e.g., securing computers);

4. Assessed or evaluated vulnerability to disasters or estimated potential loses from disasters;

5. Attended disaster meetings/training courses outside your organization;

6. Held disaster-related workshops or trainings within your organization; 
7. Discussed in an organizational meeting long-term strategies for recovery from disasters;

8. Provided information to customers/members of the community on issues related to disasters;

9. Arranged site visits by consultants or experts to better prepare for disasters; and

10. Engaged in structural mitigation measures (e.g., strengthening parts of a building).

These ten activities offer an array of different risk-reducing activities that an organization may undertake. The intent was to capture a full range of activities from low effort to high effort with some activities serving as stepping stones for other activities. Low-effort activities include, for example, mentioning a potential disaster in an organizational meeting. High-effort activities include engaging in structural mitigation. Since some low-effort activities are often prerequisites for high-effort activities; all these activities are interrelated and not mutually exclusive. For instance, if respondents answer "yes" for engaged in structural mitigation, they are also likely to answer "yes" for mentioned a potential disaster in an organizational meeting. We discuss the limitations of these measures in more detail in the conclusion.

\section{Independent variables}

The survey asked, "Please indicate the extent to which the following statements are obstacles to disaster planning in your organization". We presented respondents with a list of six obstacles measured on a scale of $1=$ minor obstacle to $5=$ major obstacle. The six obstacles include one measure on lack of financial resources: "Lack of financial resources to prepare for disasters." There were three measures on lack of information: "Lack of convincing information about the potential impacts of disasters," "Lack of 
information about the frequency and magnitude of disasters," and "Unclear organizational benefits from disaster planning and mitigation." There were two measures on lack of support: "Lack of support from mid- and lower-level organizational members," and "Lack of support from upper-level management within your organization." To avoid multicollinearity in the logit models, scales were created that combined by their aggregate means the three information variables (factor loadings between .81 and .88 , Cronbach's Alpha $=.81$ ) and the two support variables (factor loading equal to .95, Cronbach's Alpha $=.88)$.

\section{Control variables}

We operationalized Organizational size by the number of employees in an organization. The distribution of employee size is 1-9 $(n=37), 10-19(n=22), 20-49$ $(n=30), 50-99(n=32), 100-249(n=47), 250-499(n=33)$, and $\geq 500(n=14)$. In the logit models, we use employee size as clusters to minimize correlated errors within categories. The organizations in this dataset represent a wide range of sectors, the most prominent are (i) health services ( $\mathrm{n}=31$ ); (ii) retail trade ( $\mathrm{n}=23$ ); (iii) educational services ( $\mathrm{n}=19)$; (iv) wholesale trade ( $\mathrm{n}=18)$; (v) manufacturing ( $\mathrm{n}=17)$; and (vi) general services $(\mathrm{n}=29)$. The dataset also includes organizations representing churches, real estate, construction, banks, utilities, and recreational services. In the logit models, we use the Educational sector, Health sector, and Wholesale/Retail trade as dichotomous variables and the remaining as the baseline. 


\section{Results}

Figure 1 shows the ten disaster risk-reducing activities ranked by the proportion of responding organizations that engaged in each activity. For example, nearly $60 \%$ of responding organizations reported that they "mentioned a potential disaster in an organizational meeting." The most common activities involve low effort or are indicative of activities indirectly related to actual risk reduction. For example, more than half of the responding organizations "mentioned a potential disaster in an organizational meeting" or “discussed in an organizational meeting short-term responses to disasters". Nevertheless, $60 \%$ of organizations in the sample engaged in non-structural mitigation (e.g., securing computers) and assessed or evaluated vulnerability to disasters or estimated potential losses from disasters - two activities that possibly require high effort and that are more directly related to reducing risks. The least mentioned activities, as mentioned by approximately a quarter of respondents, possibly require more effort, such as providing information to customers or members of the community, arranging site visits by consultants, and engaging in structural mitigation. The findings from Figure 1 are consistent with that of Dahlhamer and D'Souza (1997) who found that the most frequent preparedness activity businesses in Memphis engaged in are the "more generic type" (e.g., having first aid kit or extra medical supplies and attending meetings).

-INSERT FIG. 1-

Table 1 shows the percentages of respondents at each obstacle level and the means for the six measures of obstacles. For instance, 10 percent of responding organizations view lack of financial resources as a minor obstacle to prepare for disasters and 35 percent of responding organizations consider lack of financial resources a major 
obstacle to disaster preparedness. The obstacles list in Table 1 are ranked by their overall means from lack of financial resources scoring the highest $($ mean $=3.0)$ to lack of support from upper-level management scoring the lowest (mean $=2.0$ ).

Responding organizations' scores for lack of financial resources are uniformly distributed. The distribution of responding organizations shifts to the left with considerably more considering lack of support from mid- and lower-level members as well as upper-level members as minor obstacles. An average respondent mentioned lack of financial resources as the most severe obstacle. In comparison, an average respondent views lack of information about the frequency and magnitude of disasters and lack of convincing information about the potential impacts of disasters as moderate obstacles to disaster preparedness, with means just above the center of the five-point scale. For the organizational support and information scales (not shown in Table 1), the means are 2.0 for the former and 2.7 for the latter (standard deviations are 1.1 and 1.2, respectfully).

\section{-INSERT TABLE 1-}

Table 2 gives the predicted probabilities of the multivariate Logit analysis. For example, as lack of information shifts from its minimum (minor obstacle) to maximum (major obstacle), there is a $73 \%$ decrease in the probability of holding workshops, holding all other variables constant at their means. We listed the risk-reducing activities from left to right by their Pseudo $\mathrm{R}^{2}$. The three obstacle classifications are on the left and below them are the controls - dichotomous variables for education sector (e.g., schools) health sector (e.g., hospitals), and wholesale and retail sector (e.g., wholesale burglary alarm systems and restaurants, respectively). We calculated robust standard errors by organizational size and the models show adequate fit with the Pseudo $\mathrm{R}^{2}$, ranging from 
0.18 for held disaster-related workshops/trainings within the organization to 0.03 for engaged in non-structural mitigation.

The most consistently significant obstacle in Table 2 is the lack of information scale. The predicted probabilities for the lack of information scale are always negative and significant in six of the ten dependent variables. Shifts from the minimum to maximum on the lack of information scale are associated with decreases in probabilities for the dependent variables ranging from $42 \%$ to $73 \%$. Lack of information tends not to be a significant factor for activities most frequently done by responding organizations: engaged in non-structural mitigation, discussed short-term responses, and mentioned disasters in a meeting (nearly $60 \%$ of respondents from Figure 1). Thus, it is possible that information is an important indicator that is associated with organizations that do more than just talk about disasters with little action or effort.

\section{-INSERT TABLE 2-}

Lack of financial resources is significant in two of the ten activities. For one, mentioning a potential disaster in an organizational meeting, the sign is negative. As the lack of financial resources shifts from a minor to major obstacle, the probability of mentioning a disaster in a meeting drops by $19 \%$. However, the sign is positive for the other significant relationship. The probability of attending disaster-related meetings/training courses outside an organization increases by $16 \%$ as financial resources shifts from a minor to a major obstacle. One interpretation of this counter-intuitive finding is that organizations seek assistance from outside their organization to provide needed information for their internal operations, a finding that is at least consistent with resource dependence theory (Pfeffer and Salancik 1978). One possible explanation might 
be that risk managers are using their connections/network to organize disaster-related workshops /trainings at no cost to their organizations.

The lack of support scale is significant for two of the dependent variables but the sign is an unexpected positive. Indeed, the sign for lack of support is positive - though not always significant - for nine out of ten dependent variables. Responding organizations are $43 \%$ more likely to attend disaster-related meetings outside their organization as lack of support shifts from a minor to a major obstacle. The other significant and positive relation for lack of support is for structural mitigation. The probability for an organization to engage in structural mitigation increases by $37 \%$ as lack of support shifts from a minor to a major obstacle. There are a couple interpretations for positive relations between lack of support and an increase in risk-reducing activities. For attending disaster-related meetings outside their organization, the finding possibly reflects organizations seeking information that members within their organization are not providing. Alternately, when organizations structurally mitigate, obstacles - such as lack of organizational support- become more apparent. Similarly, organizations that never tried a risk-reducing activity might not be as familiar with the presence of an obstacle from within their organization.

Among the controls, Table 2 shows wholesale/retail, education, and health sectors, compared to "other" organizations, are significantly more likely to engage in many of the risk-reducing activities. This finding is contrary to that of Dahlhamer and D’Souza (1997), who found that there is no difference in preparedness between wholesale/retail sector and "other" businesses. Organizations from the education sector, in contrast, are less likely to engage in risk-reducing activities. 
We end this section with a brief summary of an alternate analysis. We aggregated the ten activities by taking their overall mean into one single risk-reducing variable. We then ran an ordinary least square regression model with the same independent variables as in Table 2. The results provide support for the trends in Table 2 by showing that lack of information is the only significant obstacle with a negative sign and wholesale/retail, education, and health sectors are significant controls.

\section{Conclusions}

A major preoccupation for practitioners and researchers involved in disaster management is developing an understanding of the factors associated with risk reduction based on empirical and systematically collected data (e.g., Lindell and Whitney 2000; Lindell and Prater 2002; Whitney et al. 2004). In this study, we investigate the independent effect of three categories of organizational obstacles on organizational engagement in ten risk-reducing activities. We started this study with two research questions; we now respond to them.

What risk-reducing activities do organizations engage in? We find that organizations are most likely to engage in low-effort activities often indirectly linked to actual risk reduction (e.g., mentioned a potential disaster in an organizational meeting) and less likely to engage in high-effort activities more directly linked to risk reduction (e.g., engaged in structural mitigation measures). While not expected, this finding directs outreach toward helping organizations shift their talk into action. This result is also consistent with that of Dahlhamer and D'Souza (1997) who found generic risk-reducing activities to be more common than specific risk-reducing activities. 
To what extent do organizational obstacles affect the adoption of disaster riskreducing activities? The findings show that the most significant of all the obstacles is lack of information scale. This obstacle was not only significant in six of the ten riskreducing activities; it had the expected negative signs. Lack of information was also significant for some of the more action-oriented activities, such as structural mitigation, vulnerability assessments, attending meetings outside their organization, holding disaster related workshops, discussing long-term strategies for recovery from disasters, and arranging site visits by consultants or experts to better prepare for disasters. Lack of financial resources and support are less important obstacles. Contrary to expectations, lack of financial resources and lack of organizational support may be associated with organizations attending meetings outside their organization. Lack of organizational support may also be associated with structural mitigation - a counterintuitive finding that may suggest that obstacles are more apparent when risk-reducing activities are undertaken. While the framing of this analysis only tangentially builds from the theoretical underpinnings in organizational theory, the findings do provide support to the argument, that organizations' activities reflect their dependence on external resources, specifically information (e.g., Pfeffer and Salancik 1978)

Two lessons stand out from the current analysis. First, this analysis shows that many organizations are engaged in activities that are precursors to more direct riskreducing activities, such as mentioning a potential disaster in an organizational meeting versus engaging in structural mitigation. Planning to help organizations prepare for and mitigate disaster risks should focus on providing information that might shift organizational talk into action in part because information about the frequency of 
disasters, disaster magnitude, and the benefits of planning and mitigation are associated with activities more related to actual reductions in risk. At the very least, the reported findings support outreach programs that help communicate, or even visualize, disaster risks (e.g., Sandman et al. 1994; Mae Center 2006). Second, the relationship between obstacles and risk-reducing activities is not always negative. The multivariate analyses show that obstacles can be positively associated with risk reduction. The implication is that, in some contexts, organizations might be more aware of the obstacles when attempting to reduce their risks from disasters.

Akin to the findings from any research study, the findings herein face validity threats that researchers and practitioners should respect while drawing research lessons and policy implications. There are certainly simultaneity among the independent variables and between the independent variables and the dependent variables. One could argue, for example, that the more disaster risk-reducing measures an organization adopts, the more information they obtain. Additionally, we do not have information on some independent variables relevant to disaster risk reduction, such as past disaster experience and whether organizations lease or own their business property (Dahlhamer and D'Souza 1997; Mileti 1999). While the battery of risk-reducing activities herein captures the breadth of activities, the same measures are not mutually exclusive and some measures might be unrelated to actual risk reduction. Finally, the results are perceptual, and we really do not know which of our organizations would survive until a disaster strikes. Indeed, it is quite possible that the measures used for the dependent variables are unrelated to the "true" level of organizational readiness in the wake of a disaster. Despite these limitations, we expect that the lessons herein are not limited in strict terms just to 
Memphis/Shelby County organizations. While the extent of generalizability of the reported findings is an empirical question, we expect that lessons do apply beyond our sample to other organizations, especially private organizations, in other cities, though with understandable caution.

Good science raises more questions than answers and we feel this analysis does just that. Thus, this study suggests several next steps in understanding organizational responses to disaster risk. First, while the ten activities capture a number of different risk-reducing activities, we recommend future research to investigate the relative costs in terms of time and effort for these activities and the subsequent perceived effectiveness in reducing disaster risks. Second, more research is needed to understand why organizations mentioned engaging in an activity that we think requires high effort (engaging in nonstructural mitigation measures) over those requiring low effort (e.g., attending disaster meetings/training courses within the organization). Third, we hope that future research will investigate why there is a positive relationship between some organizational obstacles and risk-reducing activities. Fourth, it would be interesting to examine to what extent senior managers tell lower level staff to adopt specific risk-reducing measures without providing the resources needed to adopt those measures. Fifth, does Memphis differ from another region of the United States with regard to the measures available to prepare for disasters? Lastly, it may interest the research community to investigate why organizations are not interested in adopting structural mitigation measures. 


\section{References}

Aldrich, H. E. and Pfeffer, J. (1976). "Environments of Organizations." Annual Review of Sociology, 2, 79-105.

Argothy, V. (2003). "Perceptions of Acceptable Levels of Performance of Different Elements in the Built Environment in the Event of a Major Earthquake." Disaster Research Center Preliminary Paper No. 331. University of Delaware, Newark, De..

Atwood, L. E. and Major, A. M. (2000). “Optimism, pessimism, and communciation behavior in response to an earthquake prediction." Public Understanding of Science, $9,1-15$.

Auf der Heide, E. (1989). Disaster Response: Principles of Preparation and Coordination. St. Louis, Mo.: C. V. Mosby.

Bass, B. M. (1997). “The future of leadership in learning organizations.” Journal of Leadership and Organizational Studies. 7(3), 18-40.

Berke, P. R. and Beatley, T. (1992). Planning for earthquakes: risks, politics, and policy. John Hopkins University Press.

Bostrom, A., Turaga, R. M. R., and Ponomariov, B. (2006). "Earthquake Mitigation Decisions and Consequences." Earthquake Spectra, 22(2), 313-327.

Burby, R. J., May, P. J., Malizia, E. E., and Levine, J. (2000). “Code Enforcement Burdens and Central City Decline." Journal of the American Planning Association, 66(2), 143-161.

Celsi, R., Wolfinbarger, M., and Wald, D. (2005). “The Effect of Earthquake Measurement Concepts and Magnitude Anchoring on Individuals' Perceptions of Earthquake Risk.” Earthquake Spectra, 21(4), 987-1008. 
Charlier, T. (2005). “THE BIG QUAKE: How ready are we?” Commercial Appeal, December 11, 2005. http://www.showme.net/ fkeller/quake/lib/memphis1.htm Dahlhamer, J. M. and D’Souza, M. J. (1997). “Determinants of business disaster preparedness in two U.S. metropolitan areas." Int. J. Mass Emerg. Disasters, 15, 265281.

Davis, M. S. (1989). "Living along the fault line: An update on earthquake awareness and preparedness in Southern California." Urban Resources, 5, 8-14.

Dillman, D. A. (2000). Mail and Internet Surveys: The Total Design Method. New York: Wiley.

DiMaggio, P. J. and Powell, W. W. (1983). “The iron cage revisisted: Institutional isomorphism and collective rationality in organizational fields." American Sociological Review, 48, 147-160.

Dooley, D., Catalano, R., Mishra, S., and Serxner, S. (1992). "Earthquake preparedness: Predictors in a community survey." Journal of Applied Social Psychology, 22, 451470.

Drabek, T. E., Mushkatel, A., and Kilijanek, T. S. (1983). Earthquake Mitigation Policy: The Experience of Two States. Boulder: Institute of Behavioral Science, University of Colorado.

Edwards, M. L. (1993). "Social location and self-protective behavior: Implications for earthquake preparedness." Int. J. Mass Emerg. Disasters, 11, 293-304.

Farley, J. E. (1998). Earthquake Fears, Predictions, and Preparations in Mid-America. Southern Illinois University Press.

Farley, J. E., Barlow, H. D., Finkelstein, M. S., and Riley, L. (1993). “Earthquake 
hysteria, before and after: A survey and follow-up on public response to the Browning forecast." Int. J. Mass Emerg. Disasters, 11, 305-322.

Flynn, J., Slovic, P., Mertz, C. K., and Carlisle, C. (1999). "Public support for earthquake risk mitigation in Portland, Oregon." Risk Analysis, 19(2), 205-216.

Jackson, E. L. (1981). "Response to earthquake hazard: The West Coast of North America." Environment and Behavior, 13, 387-416.

Jackson, E. L., and Mukerjee, T. (1974). "Human adjustment to the earthquake hazard of San Francisco, California.” Natural hazards: Local, national and global, G. F. White, eds., New York: Oxford University Press, 160-166.

Kaufman, H. (1971). The Limits of Organizational Change. Tuscaloosa: University of Alabama Press.

Kiecolt, K. J., and Nigg, J. M. (1982). "Mobility and perceptions of a hazardous environment." Environment and Behavior, 14, 131-154.

Kingdon, J. W. (1984). Agenda, Alternatives, and Public Policies. New York: Harper Collins.

Lindell, M. K. and Whitney, D. J. (2000). "Correlates of seismic hazard adjustment adoption." Risk Analysis, 20(1), 13-26.

Lindell, M. K. and Prater, C. S. (2002). "Risk area residents' perceptions and adoption of seismic hazard adjustments." Journal of Applied Social Psychology, 32, 2377-2392.

Lindell, M. K. and Perry, R. W. (2007). "Planning and Preparedness.” Emergency Management: Principles and Practice for Local Governments, W. L. Waugh,. Jr. and K. Tierney, eds., International City/County Management Association (ICMA) Press, 113-139. 
Major, A.M. (1998). “The Utility of Situational Theory of Publics for Assessing Public Response to a Disaster Prediction." Public Relations Rev., 24(4), 489-508.

May, P. J. (1986). Disaster policy implementation: managing programs under shared governance. New York: Plenum Press.

May, P. J. and Birkland, T. A. (1994). “Earthquake risk reduction: An examination of local regulatory efforts.” Environmental Management, 18, 923-937.

May, P. J. and Wood, R. S. (2003). “At the Regulatory Front Lines: Inspectors' Enforcement Styles and Regulatory Compliance.” J. of Public Admin. Res. and Theory, 13(2), 117-139.

Mid-America Earthquake (MAE) Center (2006). "MAEviz Software.” <http://mae.ce.uiuc.edu/software_and_tools/maeviz.html $>$ (June 27, 2008).

Mileti, D. S. (1999). Disasters by Design: A Reassessment of Natural Hazards in the United States. Washington, DC: Joseph Henry.

Mileti, D. S. and O’Brien, P. W. (1992). "Warning During Disasters: Normalizing Communicated Risk.” Social Problems, 39(1), 40-57.

Mulilis, J. P. and Duval, T. S. (1995). "Negative threat appeals and earthquake preparedness: A person-relative-to-event PrE model of coping with threat." Journal of Applied Social Psychology, 25, 1319-1339.

Mushkatel, A. and Nigg, J. M. (1987). “Opinion Congruence and the Formulation of Seismic Safety Policies.” Policy Studies Rev., 6, 645-656.

Nigg, J. and Tierney, K. J. (1994). "Projections of Business Disruption Due to Earthquake Effects in Memphis, Tennessee." Paper presented at the Natural Hazard Research Symposium, Louisville, KY. 
Olshansky, R. B. (1994). "Seismic Hazard Mitigation in the Central United States: The Role of the States." USGS Professional Paper No. 1538-G, United States Government Printing Office, Washington.

Olshansky, R. B. (2005). “Making a Difference: Stories of Successful Seismic Safety Advocates." Earthquake Spectra, 21(2), 441-464.

Palm, R. I. (1981). "Public Response to Earthquake Hazard Information." Annals of the Association of American Geographers, 71(3), 389-399.

Pfeffer, J. and Salancik, G. R. (1978). The External Control of Organizations: A Resource Dependence Perspective. New York: Harper and Row.

Prater, C. S. and Lindell, M. K. (2000). "Politics of Hazard Mitigation.” Nat. Hazards Rev., 1(2), 73-81.

Russell, L., Goltz, J. D., and Bourque, L. B. (1995). "Preparedness and hazard mitigation actions before and after two earthquakes." Environment and Behavior, 27, 744-770.

Sandman, P. M., Weinstein, N. D., and Miller, P. (1994). "High risk or low: how location on a "risk ladder" affects perceived risk." Risk Analysis, 14(1), 35-45.

Selznick, P. (1957). Leadership in Administration. New York: Harper and Row.

Shepard, S. (2003). "Businesses get creative in wake of storm.” Memphis Business Journal Online, August 1, 2003. http://memphis.bizjournals.com/memphis/stories/2003/08/04/story4.html

Showalter, P. S. (1993). “Prognostication of doom: An earthquake prediction's effect on four small communities.” Int. J. Mass Emerg. Disasters, 11, 279-292.

Sullivan, R., Mustart, D. A., and Galehouse, J. S. (1977). "Living in earthquake country." California Geology, 30, 3-8.

Tierney, K. J. (1997). “Impact of recent disasters on businesses: The 1993 Mid-west floods and the 1994 Northridge earthquake." Economic Consequences of 
Earthquakes: Preparing for the Unexpected, Barclay G. Jones, eds, National Center for Earthquake Engineering Research, 189-222.

Tierney, K. J. (2006). "Businesses and Disasters: Vulnerability, Impact, and Recovery." Handbook of Disaster Research, H. Rodriquez, E. L. Quarantelli, and D. Russell, eds, Springer, 275-296.

Turner, R. H. (1983). "Waiting for disaster: Changing reactions to earthquake forecasts in Southern California." Int. J. Mass Emerg. Disasters, 1, 307-334.

United States Geological Service (USGS). (1993). "Historical Earthquakes." $<$ http://earthquake.usgs.gov/regional/states/events/1811-1812.php> (July 13, 2007).

United States Geological Service (USGS). (1998). “The Mississippi Valley-"Whole Lotta Shakin' Goin' On"." <http://quake.usgs.gov/prepare/factsheets/NewMadrid/> (March 20, 2007).

Webb, G. R., Tierney, K. J., and Dahlhamer, J. M. (2000). “Business and Disasters: Empirical Patterns and Unanswered Questions." Nat. Hazards Rev., 1(2), 83-90.

Whitney, D. J., Lindell, M. K., and Nguyen, D. H. (2004). “Earthquake belief and adoption of seismic hazard adjustments.” Risk Analysis, 24(1), 87-102.

Wood, R. S. (2004). "Earthquake entrepreneurs: Local policy systems and the regulation of public risks in California." State and Local Government Rev., 36(3), 198-211.

Wyner, A. J. and Mann, D. E. (1986). Preparing for Calilfornia's Earthquakes: Local Government and Seismic Safety. Institute of Governmental Studies, University of California, Berkeley.

Yukl, G. (1989). Leadership in Organizations. Upper Saddle River, NJ: Prentice Hall. 


\section{Acknowledgments}

The National Science Foundation funded this project through the MAE Center. Research collaborators include Dr. Rob Olshansky (with Divya Chandrasekhar, GRA) and Dr. Arleen Hill (with Jeremy Bateman, GRA). The opinions expressed belong solely to the authors. The authors thank our research collaborators for their research assistance and the following individuals for their comments: Dr. W. L. Waugh, Dr. G. Lewis, Dr. P. Kagundu, and Dr. D. Noonan. 
Table 1. Percentages of respondents at each obstacle level and obstacle means

\begin{tabular}{|c|c|c|c|c|c|c|}
\hline Independent Variables (Obstacles) & $\begin{array}{c}1 \\
\text { (Minor) }\end{array}$ & 2 & 3 & 4 & $\begin{array}{c}5 \\
\text { (Major) }\end{array}$ & Mean \\
\hline $\begin{array}{l}\text { Lack of financial resources to prepare for } \\
\text { disasters }(n=204)\end{array}$ & $19 \%$ & $19 \%$ & $27 \%$ & $12 \%$ & $24 \%$ & 3.0 \\
\hline $\begin{array}{l}\text { Lack of convincing information about the } \\
\text { potential impacts of disasters }(n=196)\end{array}$ & $28 \%$ & $14 \%$ & $26 \%$ & $21 \%$ & $12 \%$ & 2.8 \\
\hline $\begin{array}{l}\text { Lack of information about the frequency and } \\
\text { magnitude disasters }(n=195)\end{array}$ & $27 \%$ & $19 \%$ & $28 \%$ & $15 \%$ & $11 \%$ & 2.7 \\
\hline $\begin{array}{l}\text { Unclear organizational benefits from disaster } \\
\text { planning and mitigation }(\mathrm{n}=193)\end{array}$ & $33 \%$ & $18 \%$ & $22 \%$ & $15 \%$ & $11 \%$ & 2.5 \\
\hline $\begin{array}{l}\text { Lack of support from mid- and lower-level } \\
\text { organizational members }(n=181)\end{array}$ & $43 \%$ & $25 \%$ & $23 \%$ & $5 \%$ & $4 \%$ & 2.0 \\
\hline $\begin{array}{l}\text { Lack of support from upper-level } \\
\text { management within your organization }(n=183)\end{array}$ & $52 \%$ & $20 \%$ & $14 \%$ & $6 \%$ & $8 \%$ & 2.0 \\
\hline
\end{tabular}


Table 2. Changes in Predicted Probabilities for disaster risk-reducing activities from Logit Models

\begin{tabular}{|c|c|c|c|c|c|c|c|c|c|c|}
\hline & $\begin{array}{l}\text { Held } \\
\text { Work } \\
\text { Shops }\end{array}$ & $\begin{array}{l}\text { Attended } \\
\text { Meeting } \\
\text { Outside } \\
\text { the Org. }\end{array}$ & $\begin{array}{l}\text { Vul. } \\
\text { Ass't to } \\
\text { Estimate } \\
\text { Losses }\end{array}$ & $\begin{array}{l}\text { Provide } \\
\text { Info. To } \\
\text { Custom } \\
\& \\
\text { Comm. }\end{array}$ & $\begin{array}{l}\text { Structural } \\
\text { Mitigation }\end{array}$ & $\begin{array}{l}\text { Long- } \\
\text { Term } \\
\text { Response }\end{array}$ & $\begin{array}{l}\text { Site } \\
\text { Visit by } \\
\text { Experts }\end{array}$ & $\begin{array}{l}\text { Mention } \\
\text { Disaster } \\
\text { in } \\
\text { Meeting }\end{array}$ & $\begin{array}{l}\text { Short-term } \\
\text { Response }\end{array}$ & $\begin{array}{l}\text { Non- } \\
\text { Structural } \\
\text { Mitigation }\end{array}$ \\
\hline $\begin{array}{l}\text { Lack of Financial Resources } \\
\text { Lack of Organizational }\end{array}$ & 0.00 & $0.16^{*}$ & -0.20 & -0.08 & -0.07 & -0.11 & 0.06 & $-0.19^{+}$ & -0.19 & -0.15 \\
\hline Support Scale & 0.31 & $0.43^{+}$ & 0.22 & 0.14 & $0.37 *$ & 0.14 & 0.04 & 0.05 & -0.10 & 0.20 \\
\hline Lack of Information Scale & $-0.73^{ \pm}$ & $-0.66^{+}$ & $-0.43^{+}$ & -0.11 & $-0.42^{ \pm}$ & $-0.43^{*}$ & $-0.42^{ \pm}$ & -0.10 & -0.05 & -0.11 \\
\hline Education Sector & $0.26^{+}$ & 0.23 & $0.33 *$ & $0.42^{*}$ & 0.00 & 0.23 & 0.12 & 0.18 & $0.20^{+}$ & 0.12 \\
\hline $\begin{array}{l}\text { Health Sector } \\
\text { Wholesale and Retail Sector }\end{array}$ & $\begin{array}{l}0.18^{*} \\
-0.35^{ \pm}\end{array}$ & $\begin{array}{l}0.28^{*} \\
-0.33^{*}\end{array}$ & $\begin{array}{l}0.04 \\
-0.42^{ \pm}\end{array}$ & $\begin{array}{l}0.21 \\
-0.25^{ \pm}\end{array}$ & $\begin{array}{l}-0.01 \\
-0.22 *\end{array}$ & $\begin{array}{l}0.14 \\
-0.31^{ \pm}\end{array}$ & $\begin{array}{l}-0.06 \\
-0.17\end{array}$ & $\begin{array}{l}0.15 \\
-0.29 *\end{array}$ & $\begin{array}{l}0.22 \\
-0.10\end{array}$ & $\begin{array}{l}0.21^{ \pm} \\
-0.08\end{array}$ \\
\hline Pseudo $\mathrm{R}^{2}$ & 0.18 & 0.16 & 0.14 & 0.14 & 0.11 & 0.10 & 0.09 & 0.09 & 0.07 & 0.03 \\
\hline $\mathrm{N}$ & 161 & 162 & 160 & 160 & 162 & 161 & 161 & 160 & 162 & 161 \\
\hline
\end{tabular}

Note: The numbers indicate changes in predicted probability of the dependent variable as the independent variables change from their minimum to their maximum holding other independent variables at their means. Robust standard errors clustered by seven organizational sizes. ${ }^{ \pm} \mathrm{p}<0.001,{ }^{+} \mathrm{p}<0.01,{ }^{*} \mathrm{p}<0.05$ 


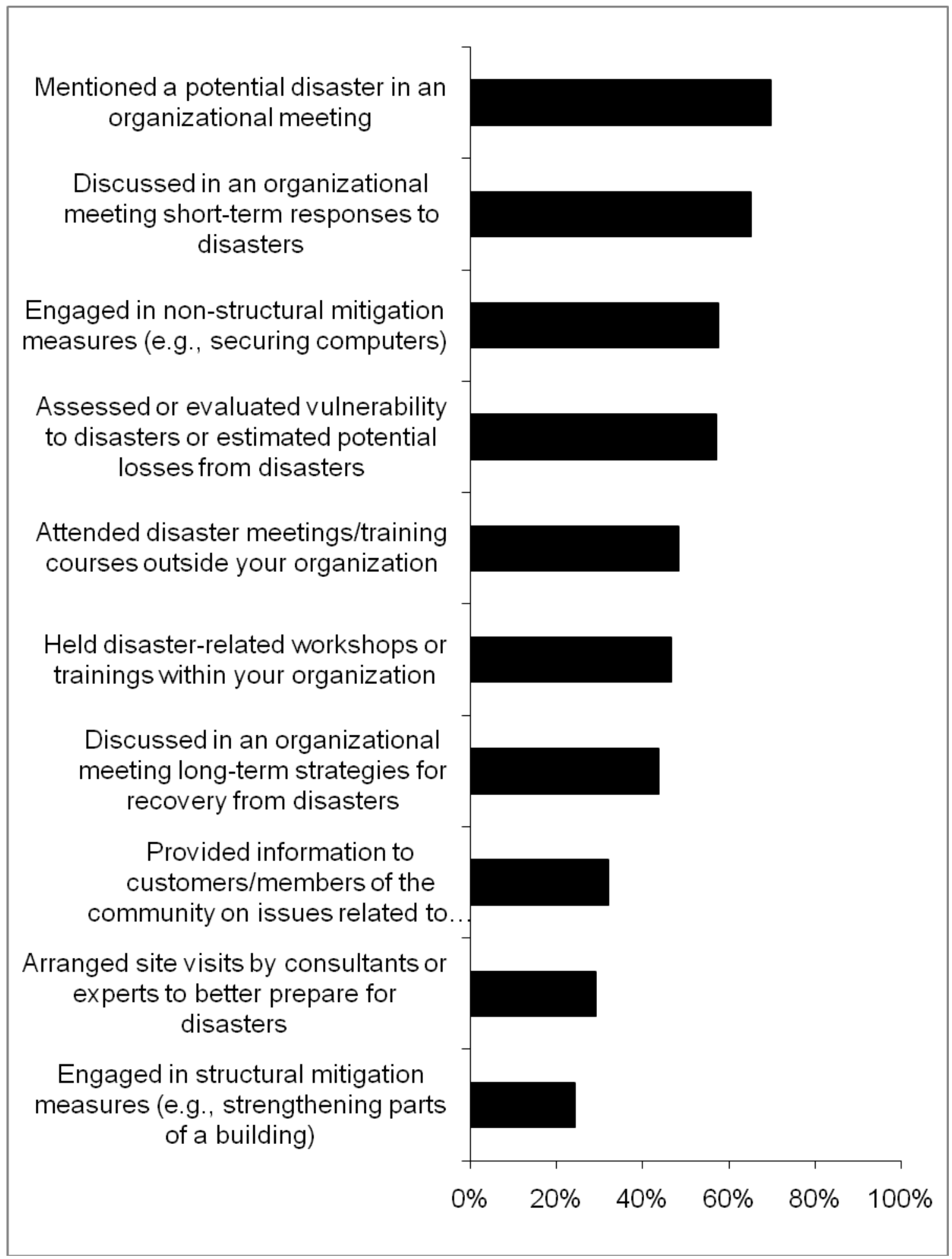

Fig. 1. Dependent variables: Disaster risk-reducing activities taken by organizations in Memphis, Tennessee. 